\title{
Growth and Yield Computer Simulation Models for Management of Sri-Lanka Even-Aged Teak Plantations.
}

\author{
Don Piyatileka Munaweera \\ B.Sc.(Hon),Post-Graduate Diploma in Statistics.
}

Thesis submitted to the University Sri Jayawardenapura for the award of the Degree of Master of Philosophy in Forestry on Growth and Yield Computer Simulation Models for Management. 


\section{DECLARATION}

I declare that this thesis is the result of my own investigation and that it has not already been accepted in whole or in part for any degree, nor is it being concurrently submitted in candidature for any degree.

Candidate

Supervisor

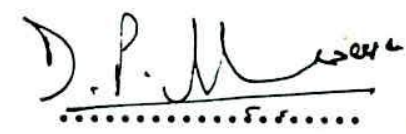

(D.P Munaweera.)

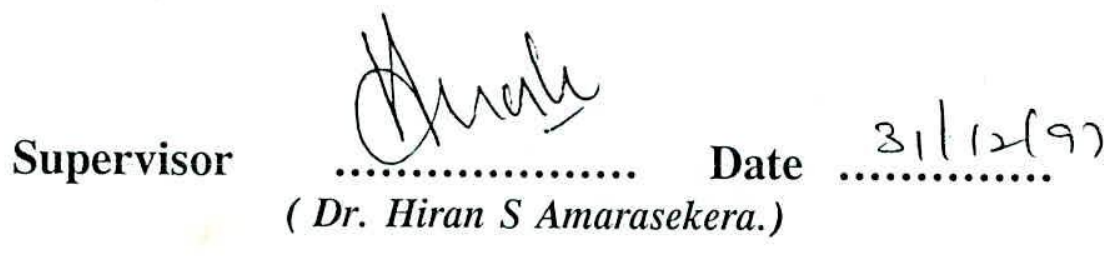

Supervisor

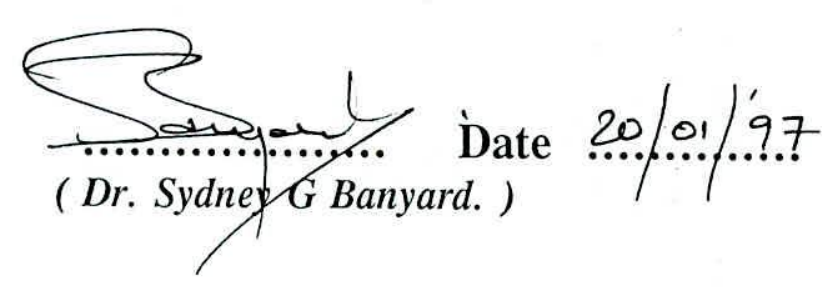




\section{Summary}

Teak in Sri Lanka has been planted to meet the industrial timber requirements especially in the furniture industry. These plantations are widely spread in the Dry zone and the Intermediate climatic zones of the country. Based on the dominant height growth variations the major teak growing areas have been geographically zoned into three major zones: namely North Central Zone, North-Western Zone and South-East Dry Zone. Due to the high mean DBH and mean height growth variations observed within Zone 2, one district (Puttalama) has been further divided into two sub-zones. For each zone and sub-zone, three site classes have been created.

Based on felled tree measurements, three volume models were fitted for each zone. Based on temporary sample plot measurements for each site class, mean DBH growth models, mean total height growth models, (both multivariate and linear) and Basal area growth models were developed. Based on these models, the CAI and MAI curves were compiled using computer models and biological rotation ages for each site class. Using rotation age, per hectare basal area growth (based on age and the stocking density) and the per mean tree basal area increment curves, proper thinning regimes were compiled. This was also done using computer models. Finally, all models, functions, rotation ages and thinning regimes were used in a computer simulation model and compile provisional yield tables for each site class under each geographical zone. In addition to the above, based on field experience and the work of 
other specialists, basic silvicultural treatment regimes for each site class were derived.

Finally all the above models, thinning regimes, silvicultural regimes, other indices values, premature clear felling indices, minimum number of trees indices for thinning operations, minimum basal area indices for later thinning and operation frequencies were incorporated in the Forest Management System (FMS) computer package to generate stand description and prescriptions for each and every teak stand in the country, and also used to compile MICRO level and MACRO level planning information which can be used in the Management planning and Work plans.

The following related studies are recommended as a follow-up to this research project: Collect new data to test the models developed and refine these where necessary; calculate taper series for teak in different zones; investigate the high growth variations observed in one of the Zone 2 sub-zones (Puttalama) and try further stratification or incorporate new variables to minimize this variation. It is also recommended to carry out economic rotation analysis to maximize the economic returns of these plantations and to refine the thinning regimes where required. Finally it is recommended that GIS facilities are applied to produce proper operation type base maps and to indicate areas suitable for raising teak plantations by incorporating appropriate indices for productivity for site selection. It is also recommended to maintain good plantations as profit centers in order to encourage the private sector to participate in the plantation forest industry. 


\section{Acknowledgement}

I would like to offer my sincere thanks to Dr. Hiran Amerasekera, M.Sc. Course Coordinator of the Department of Forestry and Environmental Science, University of Sri Jayawardenapura, for his interest in this study and for giving support and encouragement throughout my research activities.

I would also like to thank Dr Sydney Banyard ODA Forestry Education Advisor at the Department of Forestry and Environmental Science, who, by his consistent pointed questioning, forced me to spend time on explaining logically the steps followed through this long and often repetitive process of analysis. He also contributed considerably in editing this thesis and his suggestions were most welcome. His patience and questioning has definitely improved the quality of presentation.

I also wish to acknowledge the generous assistance I received from Mr. M.Pushparajah and Mr. Ernest Docknal. Having worked together with these specialists in Forest Management has inspired me to continue with my studies in this field and given me confidence to undertake this research project. Also, I owe a debt of gratitude to Mr. O.Baykal of the World Bank, Mr. S. Muttiah and Mr.S. Andel of the F.A.O for their support in introducing the Forest Management System (FMS) package, which was developed in Sri Lanka by the author, to other countries ( Nigeria, Jordan, Bangladesh, South Korea and Vietnam).

Finally I express my heart felt thanks to Mrs. Predeepika and Mrs. Thamara Kumari Seneviratne for the growth data entry and word processing support given to me in the preparation of this thesis.

D.P Munaweera. 
GROWTH AND YIELD SIMULATION MODELS FOR MANAGEMENT

OF SRI LANKAN EVEN-AGED TEAK PLANTATIONS.

LIST OF CONTENTS

SUMMARY

ACKNOWLEDGEMENT

LIST OF CONTENTS

LIST OF APPENDICES

LIST OF GRAPHS

LIST OF TABLES

CHAPTER 1: INTRODUCTION

1.1 Background

1.2 Objectives of the Study

1.3 Existing Teak Plantations in Sri Lanka

1.4 Distribution of Teak

1.5 Literature Review

1.6 Terms and Definitions

1.7 Sampling Techniques

\section{CHAPTER 2: $\quad$ METHODOLOGY}

2.1 Zoning and Site Classification

2.2 Volume modelling

2.3 Growth modelling

2.4 Rotation Periods

2.5 Thinning regimes

2.6 Simulation Models 


\section{CHAPTER 3 : DATA COLLECTION}

3.1 Introduction

3.2 Growth data measurement

- $\quad$ Sample survey method

- Sample plots

- Data cross checking

- Sample data collection

3.3 Tree Volume Calculation

- $\quad$ Sample method used

- $\quad$ Fell tree measurements

3.4 Office data compilation

3.5 Computer database

\section{CHAPTER 4 : ZONING and SITE CLASSIFICATION}
4.1 Introduction
4.2 Zoning
4.3 Site Classification
4.4 Site classes
4.5 Discussion

\section{CHAPTER 5 : VOLUME MODELLING}
5.1 Introduction
5.2 Volume modelling
5.3 Discussion

\section{CHAPTER 6 : DBH GROWTH MODELLING}
6.1 Introduction
6.2 Zone 1 Mean DBH Growth Analysis
6.3 Zone 2 Mean DBH Growth Analysis
6.4 Zone 3 Mean DBH Growth Analysis
6.5 Discussion 
CHAPTER 7 : MEAN TOTAL HEIGHT GROWTH MODELLING

7.1 Introduction

7.2 Zone 1 Mean Height Growth

7.3 Zone 2 Mean Height Growth

7.4 Zone 3 Mean Height Growth

7.5 Discussion

CHAPTER 8 : MEAN BASAL AREA GROWTH MODELLING

8.1 Introduction

8.2 Basal Area Growth Models

8.3 Zone 1 Mean Basal area Growth

8.4 Zone 2 Mean Basal area Growth

8.5 Zone 3 Mean Basal area Growth

CHAPTER 9: $\quad$ BIOLOGICAL ROTATION, THINNING REGIMES and PROVISIONAL YIELD TABLES.

9.1 Introduction

9.2 Biological rotation

9.3 Thinning regimes

9.4 Provisional Yield Tables

CHAPTER 10 : SIMULATION MODEL

10.1 Introduction

10.2 FMS Computer Simulation Model

10.3 Parameter Card used in the Model

10.4 Sample results

CHAPTER 11: D IS CUSSION CONCLUSIONS and RECOMMENDATIONS

11.1 Discussion

11.2 Conclusions

11.3 Recommendations

- Recommendations based on study findings

- $\quad$ Recommendation for further improvements

\section{REFERENCES}

APPENDICES 


\section{LIST OF APPENDICES}

\section{APPENDIX 1.}

Appendix 1.1

Figure A.1.1

Figure A.1.2

Figure A.1.3

Figure A.1.4

Figure A.1.5

Figure A.1.6

Figure A.1.7

Figure A.1.8

Figure A.1.9

\section{APPENDIX 3.}

Appendix 3.1

Appendix 3.2

\author{
Anuradhapura Teak Area Map. \\ Polonnaruwa Teak Area Map. \\ Puttalama Teak Area Map. \\ Kurunegala Teak Area Map. \\ Matale Teak Area Map. \\ Monaragala Teak Area Map. \\ Hambantota Teak Area Map. \\ Ratnapura Teak Area Map. \\ Ampara Teak Area Map.
}

Plantation Survey field instructions, Field Form for Sample Plot Measurements, Summary form for the sub block, Plantation Unit Card.

Total List of Computer files and data bases used in the analysis.

\section{APPENDIX 4.}

Appendix 4.1

\section{Teak Zone classification}

Figure A.4.1

Figure A.4.2

Figure A.4.3

Figure A.4.4

Figure A.4.5

Figure A.4.6
Puttalama data with Zone 1 curves. Kurunegala data with Zone 1 curves. Matale data with Zone 1 curves.

Ampara data with Zone 1 curves.

Monaragala data with Zone 1 curves. Hambantota data with Zone 1 curves.

Appendix 4.2

Figure A.4.7

Figure A.4.8

Figure A.4.9

Figure A.4.10

Figure A.4.11
Teak Zone Classification

Ampara data with Zone 2 curves.

Monaragala data with Zone 2 curves.

Hambantota data with Zone 2 curves.

Monaragala data with Ampara trend curves. Hambantota data with Ampara Trend curves

vii. 
Appendix 4.3

Appendix 4.4

APPENDIX 5.

Appendix 5.1
Details of Site index curves using Common slope and Common intercept methods.

Chi-square Goodness of Fit analysis.

True and Estimated Volume Comparison

Figure A.5.1

Figure A.5.2

Figure A.5.3

Figure A.5.4

Figure A.5.5

Figure A.5.6

Appendix 5.2 using Model 2 for Teak Zone 1. using Model 3 for Teak Zone 1. using Model 2 for Teak Zone 2. using Model 3 for Teak Zone 2 . using Model 2 for Teak Zone 3. using Model 3 for Teak Zone 3.

Details of regression analysis and Chi Square goodness of fit test values.

\section{APPENDIX 6.}

Appendix 6.1

Estimated and Actual DBH growth curves for Zone 1 Teak site class II

Figure A.6.1 Figure A.6.2

Figure A.6.3 using model 1. using model 2.

Mean DBH growth curves.

Estimated and Actual DBH growth curves for Zone 1 Teak site class III

Figure A.6.4

Figure A.6.5

Figure A.6.6

Table T.6.1

Table T.6.2 using model 1. using model 2.

Mean DBH growth curves.

Mean DBH Value table using Model 1 for Site class II in Zone 1 Teak.

Mean DBH Value table using Model 1 for Site class III in Zone 1 Teak.

viii. 
Appendix 6.2

Estimated and Actual DBH growth curves for Zone

2 Sub-zone 1 Teak: site class II

Figure A.6.7

Figure A.6.8

using model 1 .

Figure A.6.9 using model 2.

Mean DBH growth curves.

Estimated and Actual DBH growth curves for Zone

2 Sub-zone 1 Teak: site class III

Figure A.6.10 using model 1.

Figure A.6.11 using model 2.

Figure A.6.12 Mean DBH growth curves.

Table T.6.3 Details of ANOVA for DBH Growth Analysis for Zone 2 Sub zone 1 Teak.

Table T.6.4

Mean DBH Value table using Model 1 for Site class II in Zone 2 Sub zone 1 Teak.

Table T.6.5

Mean DBH Value table using Model 1 for Site class III in Zone 2 Sub zone 1 Teak.

Appendix 6.3

Estimated and Actual DBH growth curves for Zone

2 Sub-zone 2 Teak: site class II

Figure A.6.13

Figure A.6.14

using model 1.

using model 2.

Figure A.6.15

Mean DBH growth curves.

Estimated and Actual DBH growth curves for Zone 2 Sub-zone 2 Teak: site class III

Figure A.6.16

Figure A.6.17

Figure A.6.18

Table T.6.6

Table T.6.7

Table T.6.8 using model 1. using model 2.

Mean DBH growth curves.

Details of ANOVA for DBH Growth Analysis for Zone 2 Sub zone 2 Teak.

Mean DBH Value table using Model 1 for Site class II in Zone 2:Sub zone 2 Teak.

Mean DBH Value table using Model 1 for Site class III in Zone 2:Sub zone 2 Teak. ix 
Appendix 6.4

Estimated and Actual DBH growth curves for Zone

3 Teak: site class II

Figure A.6.19 using model 1.

Figure A.6.20 using model 2.

Figure A.6.21 Mean DBH growth curves.

Estimated and Actual DBH growth curves for Zone

3 Teak: site class III

Figure A.6.22 using model 1.

Figure A.6.23 using model 2.

Figure A.6.24 Mean DBH growth curves.

Table T.6.9 Details of ANOVA for DBH Growth Analysis for Zone 3 Teak.

Table T.6.10 Mean DBH Value table using Model 1 for Site class II in Zone 3 Teak.

Table T.6.11 Mean DBH Value table using Model 1 for Site class III in Zone 3 Teak.

\section{APPENDIX 7}

Appendix 7.1

Mean Height Growth : Zone 1 Teak

Table T.7.1

Table T.7.2

Table T.7.3

Appendix 7.2

Table T.7.4

Table T.7.5

Table T.7.6

Table T.7.7
Site Class I.

Site class II.

Site class III.

ANOVA Tables for all Site classes for Zone 2:Sub zone 1 Teak.

Mean Height Growth : Zone 2: Sub-zone 1 Teak

Site class I.

Site class II.

Site class III.

$\mathrm{x}$. 
Appendix 7.3

Table T.7.8

ANOVA Tables for all Site classes for Zone 2:Sub zone 2 Teak.

Mean Height Growth : Zone 2: Sub-zone 2 Teak

Table T.7.9

Table T.7.10

Table T.7.11

Appendix 7.4

Table T.7.12

ANOVA Tables for all Site classes for Zone 3 Teak.

Mean Height Growth : Zone 3: Teak

Table T.7.13

Table T.7.14

Table T.7.15
Site class I.

Site class II.

Site class III.
Site class I.

Site class II.

Site class III.

\section{APPENDIX 8}

Appendix 8.1

Basal Area Growth analysis : Teak.

Table T.8.1

Table T.8.2

Table T.8.3

Table T.8.4

Table T.8.5

Table T.8.6

Appendix 8.2

Table T.8.7

Table T.8.8
Detailed Information Zone 1:Site class I. Estimated values Zone 1 Site class I.

Detailed information Zone 1:Site class II. Estimated Values Zone 1:Site class II.

Detailed information Zone 1:Site class III. Estimated values Zone 1:Site class III.

Detailed information Zone 2: Sub-zone 1 Site class I.

Estimated Values Zone 2:Sub Zone 1 Site class I.

xi. 
Table T.8.9

Table T.8.10

Table T.8.11

Table T.8.12

Detailed information Zone 2:Sub Zone 1: Site Class II.

Estimated values Zone 2:Sub-zone 1 Site class II.

Detailed information Zone 2:Sub zone 1 Site class III.

Estimated values Zone 2:Sub-zone 1: Site class III.

Appendix 8.3

Basal Area Growth analysis : Teak.

Table T.8.13

Table T.8.14

Table T.8.15

Table T.8.16

Table T.8.17

Table T.8.18

Appendix 8.4

Table T.8.19

Table T.8.20

Table T.8.21

Table T.8.22

Table T.8.23

Table T.8.24
Detailed information Zone 2:Sub-zone 2 Site class I.

Estimated values Zone 2:Sub-zone 2 Site class I.

Detailed information Zone 2:Sub-zone 2 Site class II.

Estimated values zone 2:Sub-zone 2 Site class II.

Detailed information Zone 2:Sub-zone 2 Site class III.

Estimated values Zone 2:Sub-zone 2 Site class III.

Detailed information Zone 3: Site class I. Estimated values Zone 3:Site class I.

Detailed information Zone 3:Site class II. Estimated values Zone 3:Site class II.

Detailed information Zone 3:Site class III. Estimated values Zone 3:Site class III.

xii. 


\section{APPENDIX 9}

Appendix 9.1

CAI \& MAI Tables with growth models for Teak

Table A.9.1

Table A.9.2

Table A.9.3

Table A.9.4

Table A.9.5

Table A.9.6

Table A.9.7

Table A.9.8

Table A.9.9

Table A.9.10

Table A.9.11

Table A.9.12
Zone 1: Site class I.

Zone 1: Site class II.

Zone 1: Site class III.

Zone 2, Sub-zone 1: Site class I.

Zone 2, Sub-zone 1: Site class II.

Zone 2, Sub-zone 1: Site class III.

Zone 2, Sub-zone 2: Site class I.

Zone 2, Sub-zone 2: Site class II.

Zone 2, Sub-zone 2: Site class III.

Zone 3: Site class I.

Zone 3: Site class II.

Zone 3: Site class III.

\section{Appendix 9.2}

Provisional Yield tables for Teak

Table A.9.13

Table A.9.14

Table A.9.15

Table A.9.16

Table A.9.17

Table A.9.18

Table A.9.19

Table A.9.20

Table A.9.21

Table A.9.22

Table A.9.23

Table A.9.24
Zone 1: Site class I.

Zone 1: Site class II.

Zone 1: Site class III.

Zone 2, Sub-zone 1: Site class I.

Zone 2, Sub-zone 1: Site class II.

Zone 2, Sub-zone 1: Site class III.

Zone 2, Sub-zone 2: Site class I. Zone 2, Sub-zone 2: Site class II. Zone 2, Sub-zone 2: Site class III.

Zone 3: Site class I. Zone 3: Site class II. Zone 3: Site class III.

xiii. 